cambridge.org/cty

\section{Corrigendum}

Cite this article: Grosch IB, Andresen B, Diep LM, Diseth TH, and Möller T (2022) Quality of life and emotional vulnerability in a national cohort of adolescents living with Fontan circulation - CORRIGENDUM. Cardiology in the Young 32: 1192. doi: 10.1017/ S1047951121003802

First published online: 6 September 2021

\title{
Quality of life and emotional vulnerability in a national cohort of adolescents living with Fontan circulation - CORRIGENDUM
}

Inger Bygland Grosch, Brith Andresen, Lien My Diep, Trond H. Diseth and

Thomas Möller

DOI: https://doi.org/10.1017/S1047951121003188 Published online by Cambridge University Press: 13 August 2021

The authors apologise that within the introduction of the published article the sentence 'Quality of life and mental health in this population have not previously been studied in Norway' needed further clarification and the inclusion of additional references.

The actual and preceding sentence should read as follows:

However, specific population-based data on quality of life issues and mental health in adolescents with Fontan circulation are limited, constituting a knowledge gap. Quality of life and mental health have been studied in our institution in the general paediatric CHD population previously (47-49), but Fontan-specific studies have not been performed in Norway before.

47. Spurkland I, Bjornstad PG, Lindberg H, Seem E. Mental health and psychosocial functioning in adolescents with congenital heart disease. A comparison between adolescents born with severe heart defect and atrial septal defect. Acta Paediatr. 1993;82(1):71-6.

48. Bjørnstad PG, Spurkland I, Lindberg HL. The impact of severe congenital heart disease on physical and psychosocial functioning in adolescents. Cardiology in the Young. 1995;5(1):56-62.

49. Fredriksen PM, Diseth TH, Thaulow E. Children and adolescents with congenital heart disease: assessment of behavioural and emotional problems. European child \& adolescent psychiatry. 2009;18(5):292-300.

\section{Reference}

Grosch, I., Andresen, B., Diep, L., Diseth, T., \& Möller, T. (2021). Quality of life and emotional vulnerability in a national cohort of adolescents living with Fontan circulation. Cardiology in the Young, 1-9. doi: 10.1017/ S1047951121003188
(C) The Author(s), 2021. Published by Cambridge University Press. This is an Open Access article, distributed under the terms of the Creative Commons Attribution licence (http:// creativecommons.org/licenses/by/4.0/), which permits unrestricted re-use, distribution, and reproduction in any medium, provided the original work is properly cited. 